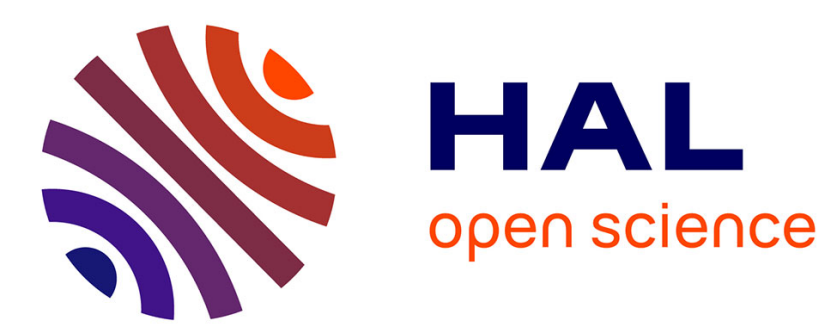

\title{
Firm-level total factor productivity convergence in German electricity and gas industry
}

\author{
Claudiu Tiberiu Albulescu, Serban Miclea
}

\section{To cite this version:}

Claudiu Tiberiu Albulescu, Serban Miclea. Firm-level total factor productivity convergence in German electricity and gas industry. 2020. hal-02512939

\section{HAL Id: hal-02512939 \\ https://hal.science/hal-02512939}

Preprint submitted on 20 Mar 2020

HAL is a multi-disciplinary open access archive for the deposit and dissemination of scientific research documents, whether they are published or not. The documents may come from teaching and research institutions in France or abroad, or from public or private research centers.
L'archive ouverte pluridisciplinaire HAL, est destinée au dépôt et à la diffusion de documents scientifiques de niveau recherche, publiés ou non, émanant des établissements d'enseignement et de recherche français ou étrangers, des laboratoires publics ou privés. 


\title{
Firm-level total factor productivity convergence in German electricity and gas industry
}

\author{
Claudiu Tiberiu ALBULESCU ${ }^{1,2 *}$, Șerban MICLEA ${ }^{1}$ \\ ${ }^{1}$ Management Department, Politehnica University of Timisoara, 2, P-ta. Victoriei, 300006 Timisoara, Romania. \\ ${ }^{2}$ CRIEF, University of Poitiers, 2, Rue Jean Carbonnier, Bât. A1 (BP 623), 86022, Poitiers, France.
}

\begin{abstract}
This paper investigates the degree of total factor productivity convergence for the German electricity and gas firms. We use different approaches to compute the productivity level and several old and new panel unit root tests from the second generation to check the existence of a convergence process. For robustness purpose we compare the convergence between small and medium-sized enterprises and large companies. Our findings show the existence of the convergence process in terms of total factor productivity, result confirmed by all categories of tests we use. Therefore, an innovation transfer is recorded between German electricity and gas firms, transfer that is slightly higher for small and medium-sized enterprises.
\end{abstract}

JEL codes: D24, O33

Keywords: total factor productivity, convergence, panel unit root tests, firm-level data, German electricity and gas industry

\footnotetext{
*E-mail: claudiu.albulescu@upt.ro.
} 


\section{Introduction}

Germany is considered one of the largest electricity exporters in the European Union (EU) and more than $40 \%$ of its electricity production comes from renewable sources (Burger, 2019). The energy provision in Germany is ensured by private and public companies of different size and performance. Within the "Electricity, gas, steam and air conditioning supply" industry (NACE code 35) in Germany operate over 7,500 firms, revealing the complexity of the energy sector. Using firm-level data, the purpose of this paper is to compute the Total Factor Productivity (TFP) for these firms within a panel framework, and to check the TFP convergence process.

At macroeconomic level, the TFP convergence is questioned starting with the pioneering paper by Solow (1975), showing that the productivity increase represents a fundamental source of economic growth. Recent empirical papers investigating this issue for different sets of countries are those of Miller and Upadhyay (2002), Solarin (2017), Burda and Severgnini (2018), Maryam and Jehan (2018) and Rath and Akram (2019).

Assessing the TFP convergence across firms has different implications. On the one hand, it allows to see if there is a productivity dispersion between firms and which are its causes (Baily et al., 1992; Oulton, 1998; Griffith et al., 2002). On the other hand, studying the TFP convergence across firms offers information about the innovation transfer within narrowly defined industries (Andrews et al., 2015). Whereas few recent studies focus on the speed of convergence (e.g. Chevalier et al., 2012), other works investigate the dispersion and convergence in terms of productivity (Cette et al., 2018), or assess the determinants of TFP in specific industries (Thabet, 2018). As far as we know, the TFP in the electricity sector is marginally investigated by See and Coelli (2014) who focus on a vertically integrated electricity utility from Malaysia, without considering the entire industry and the convergence process. Moreover, there are no studies investigating the TFP convergence for the German electricity and gas firms.

Hence, we develop this narrow strand of the literature in three ways. First, we use the Wooldridge's (2009) approach to compute the TFP for 535 German electricity and gas firms, over the period 2007 to 2015. Compared to the Levinsohn and Petrin's (2003) approach used as benchmark in our study, Wooldridge (2009) resorts to a General Method of Moments (GMM) technique to show how the variables used as a proxy for the unobserved productivity can be implemented with different instruments and equations.

Second, like Miller and Upadhyay (2002), we check the convergence process considering the group average TFP - $\sigma$-convergence. To this end, we employ classic secondgeneration panel unit root tests (i.e. Pesaran, 2003; Choi, 2006), but also the new tests proposed by Lupi (2011), which are considered more powerful in the presence of crosssectional dependence for small panels.

Finally, we consider the role of firms' size in influencing the level of TFP and we split our sample in small and medium-sized enterprises (SME) and large companies (LARGE). We document the existence of a convergence process in terms of TFP for German electricity and gas firms and we discover that the convergence is slightly higher for the SME group.

The next section of this paper presents the methodology used for computing the TFP, for estimating the convergence process, and the data employed in the analysis. Section 3 presents the convergence results whereas Section 4 is designed to show the outcome of the robustness analysis by comparing the TFP convergence between SME and LARGE companies' samples. The last section concludes. 


\section{Methodology and data}

\subsection{Methodology}

\section{A. TFP computation}

We use Wooldridge's (2009) approach for the TFP computation and the Levinsohn and Petrin's (2003) approach as benchmark. In a panel specification, the TFP is usually derived from the residual of the following regression:

$\mathrm{VA}_{\mathrm{it}}=\mathrm{c}+\alpha \mathrm{K}_{\mathrm{it}}+\beta \mathrm{L}_{\mathrm{it}}+\varepsilon_{\mathrm{it}}$,

where VA is the value added, $\mathrm{K}$ is the capital stock computed using the perpetual inventory method (PIM), $\mathrm{L}$ represents the number of employees, $\mathrm{i}=1, \ldots, 535$ firms, $\mathrm{t}=$ $2007, \ldots, 2015, c$ is a constant capturing the average performance.

The error term $\varepsilon_{i t}$ cam be decomposed into firms' observed productivity $\left(\mathrm{m}_{\mathrm{it}}\right)$, and unobserved productivity shocks $\left(\mathrm{n}_{\mathrm{it}}\right)$ :

$\varepsilon_{\mathrm{it}}=\mathrm{m}_{\mathrm{it}}+\mathrm{n}_{\mathrm{it}}$,

Levinsohn and Petrin (2003) notice a simultaneity issue between inputs and productivity shocks and solve it by identifying the demand for intermediate goods (ig ${ }_{i t}$, which are influenced by the capital stock. Therefore, Eq. (1) becomes:

$\mathrm{VA}_{\mathrm{it}}=\mathrm{c}+\alpha \mathrm{K}_{\mathrm{it}}+\beta \mathrm{L}_{\mathrm{it}}+\mathrm{h}\left(\mathrm{ig}_{\mathrm{it}}+\mathrm{K}_{\mathrm{it}}\right)+\mathrm{n}_{\mathrm{it}}, t=1 \ldots T$.

The assumptions made by Levinsohn and Petrin (2003) to restrict the productivity dynamics are considered insufficient by Wooldridge's (2009) that advance a consistent standard errors GMM approach, with different instruments $\left(\mathrm{m}_{\mathrm{it}}=\mathrm{f}\left[\mathrm{h}\left(\mathrm{ig} \mathrm{g}_{\mathrm{it}-1}+\mathrm{K}_{\mathrm{it}-1}\right)\right]+\mathrm{a}_{\mathrm{it}}\right)$, with $f$ being an invertible function and $\mathrm{a}_{\mathrm{it}}$ the innovation. Therefore, Eq. (3) becomes:

$\mathrm{VA}_{\mathrm{it}}=\mathrm{c}+\alpha \mathrm{K}_{\mathrm{it}}+\beta \mathrm{L}_{\mathrm{it}}+\mathrm{h}\left(\mathrm{ig}_{\mathrm{it}-1}+\mathrm{K}_{\mathrm{it}-1}\right)+\mathrm{a}_{\mathrm{it}}+\mathrm{n}_{\mathrm{it}}$.

\section{B. Second-generation panel unit root tests}

The two classic panel unit root tests designed for unbalanced panel data are the Choi' $\mathrm{s}$ (2006) Fisher ADF-type tests (pm, Z, L*), and Pesaran's (2003) cross-sectional ADF test from the second generation $(\mathrm{CADF})^{1}$. However, these tests are restrictive because their asymptotic requires $N \rightarrow \infty$ and $T \rightarrow \infty$. Therefore, starting from Choi's (2001) Z test, new tests are developed and do not require cross-sectional independence. Choi's (2001) test is:

$\mathrm{Z}=\frac{1}{\sqrt{\mathrm{N}}} \sum_{\mathrm{i}=1}^{\mathrm{N}} \Phi^{-1}\left(\mathrm{p}_{\mathrm{i}}\right)_{\mathrm{H}_{0}}^{\stackrel{\mathrm{d}}{\rightarrow}} \mathrm{N}(0,1)$,

where $\Phi^{-1}\left(\mathrm{p}_{\mathrm{i}}\right)$ is the inverse normal cumulative distribution function.

A different approach is proposed by Hansen (1995) who augments the standard ADF test (CADF) with a stationary covariate and obtains:

$$
\mathrm{a}(\mathrm{L}) \Delta \mathrm{y}_{\mathrm{t}}=\delta \mathrm{y}_{\mathrm{t}-1}+\mathrm{b}(\mathrm{L}) \Delta \mathrm{x}_{\mathrm{t}-1}+\mathrm{e}_{\mathrm{t}}, \quad \text { with } \quad \mathrm{a} \quad \text { t-ratio } \quad \hat{\mathrm{t}}(\delta) \stackrel{\omega}{\longrightarrow} \rho \frac{\int_{0}^{1} \mathrm{WdW}}{\left(\int_{0}^{1} \mathrm{~W}^{2}\right)^{\frac{1}{2}}}+(1-
$$

$\rho 212 \mathrm{~N} 0,1,(6)$

where $\mathrm{W}$ is a standard Wiener process.

Starting from Choi (2001) and Hansen (1995), Costantini and Lupi (2013) develop pvalue combinations and obtain the pCADF test for balanced panels. However, to overcome this limitation, Lupi (2011) use the Simes's (1986) intersection test advocated by Hanck (2013), to validate/invalidate the null of panel unit root hypothesis (sCADF test). At the same time, Lupi (2011) build upon Costantini and Lupi (2013) considering Simes' procedure and obtain a new test labelled spCADF.

\footnotetext{
${ }^{1}$ For brevity issues, we do not present these well-known tests.
} 


\subsection{Data}

We use AMADEUS statistics for the period 2006 to 2015, covering 7,559 German companies. Given that value added data is scarce in this database, we have retained into analysis only those companies for which at least six consecutive observations are available for value added (535 firms). Moreover, we use the PIM approach to compute the capital stock ${ }^{2}$ and we lose an observation (therefore, the final timespan is 2007-2015). We obtain an unbalanced panel starting from which we compute the TFP based on Wooldridge (2009) (tfp_wdrg) and Levinsohn and Petrin (2003) (tfp_lp). For robustness purpose, we make a comparison in terms of TFP between SME and LARGE companies (more than 250 employees) $)^{3}$. The summary statistics of the TFP for different samples are presented in Table 1. We notice that the average TFP computed based on Levinsohn and Petrin (2003) is closed to zero, whereas the TFP series using the Wooldridge's (2009) approach are more volatile.

Table 1. Summary statistics for TFP series

\begin{tabular}{lcccccc}
\hline & \multicolumn{2}{c}{ ALL } & \multicolumn{2}{c}{ SME } & \multicolumn{2}{c}{ LARGE } \\
\hline & tfp_wdrg & tfp_lp & tfp_wdrg & tfp_lp & tfp_wdrg & tfp_lp \\
\hline Mean & 7.218 & -0.000 & 6.949 & -0.035 & 8.323 & 0.134 \\
Std. Dev. & 1.040 & 0.769 & 0.857 & 0.748 & 1.028 & 0.847 \\
Minimum & -3.163 & -12.27 & -2.329 & -9.725 & -3.163 & -12.27 \\
Maximum & 11.91 & 5.413 & 10.38 & 3.575 & 11.91 & 5.413 \\
\hline
\end{tabular}

Notes: (i) tfp_wdrg is the TFP based on Wooldridge (2009), tfp_lp is the TFP relying on Levinsohn and Petrin (2003).

The convergence process in TFP is assessed considering the group average ( $\sigma$ convergence, as in Miller and Upadhyay (2002)). The new series are thus obtained as follows: $w d r g=t f p \_w r d g-$ AVERAGE(tfp_wdrg), and

$l p=$ tfp_lp - AVERAGE $\left(\mathrm{tfp} \_\mathrm{lp}\right)$.

To test the existence of the convergence process we employ panel unit root tests. Prior to this, we apply a series of cross-sectional dependence tests which recommend the use of second-generation panel unit root tests. As we can notice in Table 2, all tests reject the null of cross-sectional independence.

Table 2. Cross-sectional dependence tests

\begin{tabular}{lllllll}
\hline & \multicolumn{2}{c}{ ALL } & \multicolumn{2}{c}{ SME } & \multicolumn{2}{c}{ LARGE } \\
\cline { 2 - 7 } & wrdg & lp & wrdg & lp & wrdg & lp \\
\hline Breusch-Pagan LM & $224021 * * *$ & $193869 * * *$ & $145995 * * *$ & $127146 * * *$ & $8154.4 * * *$ & $6940.1 * * *$ \\
Pesaran scaled LM & $151.87 * * *$ & $95.461 * * *$ & $122.59 * * *$ & $78.911 * * *$ & $28.307 * * *$ & $16.459 * * *$ \\
Bias-corrected & & & & & & \\
LM & & & & & \\
Pesaran CD & $118.43 * * *$ & $62.023 * * *$ & $95.594 * * *$ & $51.911 * * *$ & $21.869 * * *$ & $10.022 * * *$ \\
\hline & $84.264 * * *$ & $13.296 * * *$ & $64.081 * * *$ & $9.0937 * * *$ & $19.523 * * *$ & $4.3746 * * *$ \\
\hline
\end{tabular}

Note: $* * *, * *, *$ denote statistical significance at the $1 \%, 5 \%$, and $10 \%$ level

\section{Convergence results}

Table 3 presents the results of the $\sigma$-convergence of German companies from the electricity and gas sector. We apply three tests from the second-generation panel unit root

\footnotetext{
${ }^{2} \mathrm{~K}_{\mathrm{it}}=\mathrm{K}_{\mathrm{it}}^{\mathrm{BV}}-\mathrm{K}_{\mathrm{it}-1}^{\mathrm{BV}}+\mathrm{DEPR}^{\mathrm{BV}}$, where $\mathrm{K}$ represents the tangible fixed assets and DEPR the depreciation and amortization (book value $-\mathrm{BV}$ ). If the stock of capital is negative (in $2.13 \%$ of cases), we proceed to the following transformation: $\mathrm{K}_{\mathrm{it}}^{\prime}=\left(\mathrm{K}_{\mathrm{it}}-\mathrm{MIN}\left(\mathrm{K}_{\mathrm{it}}\right)\right)+1$.

${ }^{3}$ The SME sample includes 432 firms whereas the LARGE companies sample contains 103 firms.
} 
tests: two classic tests relying on Choi (2006) and Pesaran (2003) appropriate for unbalanced panels, and the new tests proposed by Lupi (2011), which are considered more powerful in the case of small samples. For the Wooldridge's (2009) metrics of TFP (wrdg) we notice that all the tests indicate the absence of unit roots, which correspond to the existence of a convergence process in terms of productivity. This result remains practically the same for the benchmark approach used to compute the TFP series, following Levinsohn and Petrin (2003). Our findings show that the German electricity and gas companies present similar patterns in terms of TFP, and confirms the results reported by Cette et al. (2018) for the French companies.

Table 3. Panel unit root tests (entire sample)

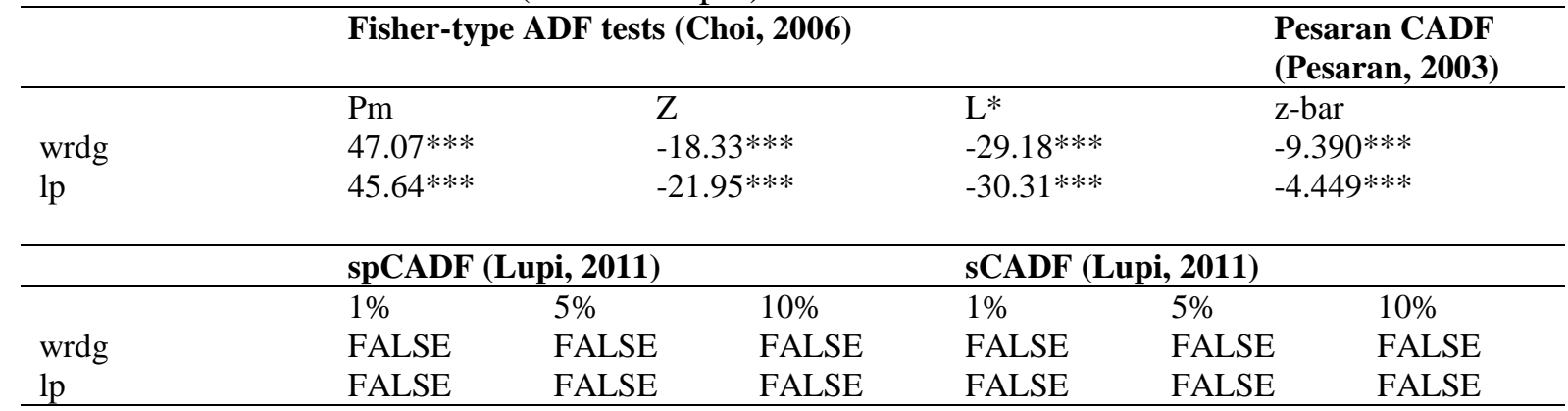

Notes: ( $i$ ) the null for all tests is the presence of unit roots; (ii) Pm, $Z$ and $L^{*}$ are the modified inverse chisquared, inverse normal and inverse logit tests; (iii) ***, **, * denote statistical significance at the 1\%, 5\%, and 10\% level (e.g. for *** the p-value < 0.01); (iv) spCADF test is advanced by Lupi (2011) based on Constantini and Lupi (2013) pCADF test; (v) sCADF test is advanced by Lupi (2011) based on Hanck (2013) CADF test; (vi) TRUE - test does not reject the null, FALSE - the null of unit roots is rejected; (vii) the lag selection for Lupi's (2011) tests is based on the AIC information criteria (maximum three lags are included).

However, the convergence results might be influenced by the composition of the sample. Specifically, to be sure that the convergence of total factor productivity does not hinge on the size of the company, we split our sample in two parts, considering SME and LARGE companies.

\section{Robustness investigation}

For the SME sample, the panel unit root tests document the convergence in terms of TFP (Table 4). This result is obtained using old and new second-generation panel unit root tests. Lupi's (2011) tests reject the null hypothesis of unit root presence at $1 \%$ significance level.

Table 4. Panel unit root tests (SME' sample)

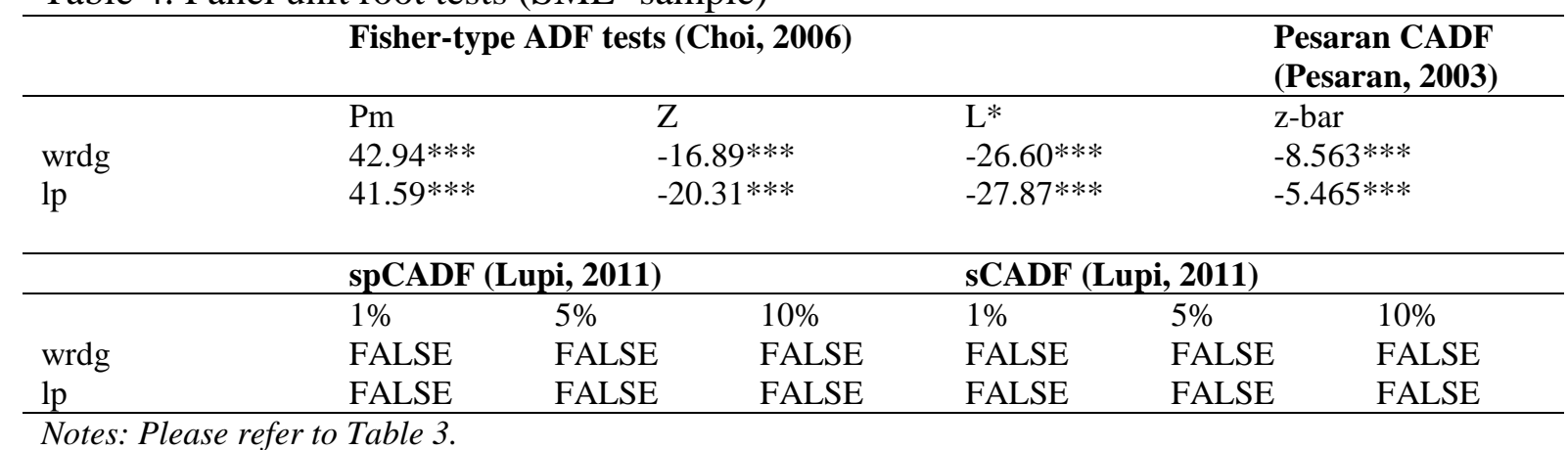


The findings presented in Table 5 confirm the initial results and prove their robustness. Therefore, the $\sigma$-convergence is noticed for large companies as well. Nevertheless, if we compare these results with those reported in Table 4 for the SMEs, the old (classic) tests present smaller coefficients, although the level of significance remains the same. Moreover, we observe that Lupi's (2011) tests reject the null only at 5\% significance level. As a results we conclude that the level of convergence is stronger for the SME compared with the LARGE companies' sample.

Table 5. Panel unit root tests (LARGE companies' sample)

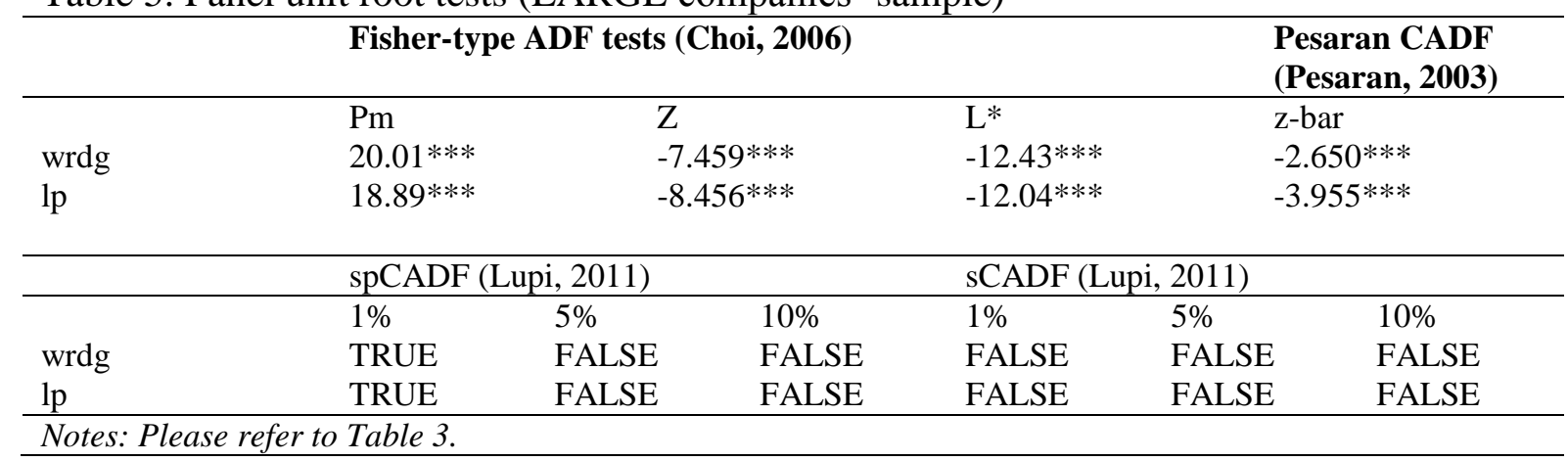

\section{Conclusion}

In this paper we have computed the TFP for 535 firms belonging to the electricity and gas industry for Germany. To this end, we have used the Wooldridge's (2009) approach, and the methodology by Levinsohn and Petrin (2003) as benchmark. In a second step, we have tested the $\sigma$-convergence, that is, we have checked the stationarity of the group-average difference-TFP series. More precisely, we have computed new series by differentiating the TFP series and the group average TFP.

By applying different classic and new panel unit root tests from the second generation, our findings show the existence of convergence process, documented by both old and new tests, as those proposed by Lupi (2011). This proves the dissemination of innovation between German electricity and gas companies. In addition, we document the $\sigma$-convergence in terms of TFP for both SME and large companies, although the convergence seems to be stronger for the small companies.

\section{References}

Andrews D., Criscuolo C., Gal P.N. (2015). "Frontier firms, technology diffusion and public policy: Micro evidence from OECD countries", OECD Productivity Working Papers 2, OECD Publishing.

Baily, M., Hulten, C., Campbell, D. (1992). "Productivity dynamics in manufacturing plants", Brookings Papers on Economic Activity: Microeconomics, 2, 187-249.

Burda, M.C., Severgnini, B. (2018). "Total factor productivity convergence in German states since reunification: Evidence and explanations", Journal of Comparative Economics, 46(1), 192-211.

Burger, B. (2019). "Net public electricity generation in Germany in 2018". Fraunhofer Institute for Solar Energy Systems ISE. Available at: 
https://www.ise.fraunhofer.de/content/dam/ise/en/documents/News/Stromerzeugung 20 18 2_en.pdf

Cette, G., Corde, S., Lecat, R. (2018). "Firm-level productivity dispersion and convergence", Banque de France, Working Paper No. 662.

Chevalier, P.A., Lecat, R., Oulton, N. (2012). "Convergence of firm-level productivity, globalisation and information technology: Evidence from France", Economics Letters, 116, 244-246.

Choi, I. (2001). "Unit root tests for panel data", Journal of International Money and Finance, 20, 249-272.

Choi, I. (2006). "Combination unit root tests for cross-sectionally correlated panels", in D. Corbae, S.N. Durlauf \& B.E. Hansen (eds), Econometric theory and practice: Frontiers of analysis and applied research, pp. 311-333, Cambridge University Press: Cambridge.

Constantini, M., Lupi, C. (2013). "A simple panel-CADF test for unit roots", Oxford Bulletin of Economics and Statistics, 75(2), 276-296.

Griffith, R., Redding, S., Simpson, H. (2002). "Productivity convergence and foreign ownership at the establishment level", Institute for Fiscal Studies, Working Paper No. $02 / 22$.

Hanck, C. (2013). "An intersection test for panel unit roots", Econometric Reviews, 32(2), 183-203.

Hansen, B.E. (1995). "Rethinking the univariate approach to unit root testing: Using covariates to increase power", Econometric Theory, 11(5), 1148-1171.

Levinsohn, J., Petrin, A. (2003). "Estimating production functions using inputs to control for unobservables", Review of Economic Studies, 70(2), 317-341.

Lupi, C. (2011). "Panel-CADF testing with R: Panel unit root tests made easy", University of Molise, Economics and Statistics Discussion Paper, No. 063/11.

Maryam, K., Jehan, Z. (2018). "Total factor productivity convergence in developing countries: Role of technology diffusion", South African Journal of Economics, 86(2), 247-262.

Miller, S.M., Upadhyay, M.P. (2002). "Total factor productivity and the convergence hypothesis", Journal of Macroeconomics, 24(2), 267-286.

Oulton, N. (1998). "Competition and the dispersion of labour productivity amongst UK companies", Oxford Economic Papers, 50, 23-38.

Pesaran, H.M. (2003). "A simple panel unit root test in the presence of cross section dependence", University of Cambridge, Cambridge Working Papers in Economics, No. 0346.

Rath, B.N., Akram, V. (2019). "A reassessment of total factor productivity convergence: Evidence from cross-country analysis", Economic Modelling, 82, 87-98.

See, K.F., Coelli, T. (2014). "Total factor productivity analysis of a single vertically integrated electricity utility in Malaysia using a Törnqvist index method", Utilities Policy, 28, 62-72.

Simes, R.J. (1986). "An improved bonferroni procedure for multiple tests of significance", Biometrika, 73(3), 751-754.

Solarin, S.A. (2017). "Testing for the stationarity in total factor productivity: Nonlinearity evidence from 79 countries", Journal of the Knowledge Economy, 8, 141-158.

Solow, R.M. (1957). "Technical change and the aggregate production function", Review of Economics and Statistics, 39(3), 312-320.

Thabet, K. (2018). "Determinants of total factor productivity growth of Tunisian manufacturing firms", Economics Bulletin, 38(1), 336-348. 
Wooldridge, J.M. (2009). "On estimating firm-level production functions using proxy variables to control for unobservables”, Economics Letters, 104(3), 112-114. 